\title{
Medial femorotibial osteoarthritis of the knee: total or partial knee replacement?
}

\author{
Jean-Noel A. Argenson, Christophe Jacquet, Matthieu Ollivier \\ Institute for Locomotion, Department of Orthopedic Surgery, Aix-Marseille University, Marseille, France \\ Correspondence to: Jean-Noel A. Argenson. Institute for Locomotion, Hospital Sainte-Marguerite, Department of Orthopedic Surgery, 270 Boulevard \\ Sainte-Marguerite, 13009 Marseille, France. Email: jean-noel.argenson@ap-hm.fr. \\ Provenance and Peer Review: This article was commissioned and reviewed by the Academic Editor Dr. Ziming Chen (Centre for Orthopaedic \\ Translational Research, Medical School, University of Western Australia, Nedlands, Australia). \\ Comment on: Beard DJ, Davies LJ, Cook JA, et al. The clinical and cost-effectiveness of total versus partial knee replacement in patients with medial \\ compartment osteoarthritis (TOPKAT): 5-year outcomes of a randomised controlled trial. Lancet 2019;394:746-56.
}

Submitted Dec 20, 2019. Accepted for publication Jan 16, 2020.

doi: 10.21037/atm.2020.01.131

View this article at: http://dx.doi.org/10.21037/atm.2020.01.131

In case of bone on bone osteoarthritis (OA) limited to the medial compartment of the knee and after failure of non-operative treatments, the orthopedic surgeon has two options. He can either decide to replace the three compartments of the knee while realizing a total knee replacement (TKR), or he can replace only the affected medial femorotibial compartment while realizing a partial knee replacement (PKR). The debate of which option between TKR and PKR offers better clinical advantages for symptomatic OA of one compartment of the knee has generated frequent controversy in the orthopedic community $(1,2)$. TKR has for many years been considered the standard of surgical treatment for knee OA due to demonstrated reproducibility and effectiveness for relieving pain and restoring function (3), however PKR has increased in popularity over the last 20 years as shown in national orthopedic registries (4).

The number of existing comparative randomized studies is limited $(1,5-7)$ with often reduced number of cases. While these studies have reported good clinical results after both PKR and TKR, there is a tendency tend to have marginally better function for PKR patients but sources of heterogeneity in type of patients might be a potential source of interference. In systematic review and meta-analysis evaluation it was clear that more patients did return to physical and sportive activities after PKR than after TKR, but again confounding factors were inadequately taken into account (8). In contrast higher frequencies of revision and reoperations with PKR have been identified using observational, registry-based study (9).

In Lancet, Beard et al. (10) evaluated the clinical results and cost-effectiveness of TKR versus PKR in patients with medial compartment $\mathrm{OA}$ of the medial compartment of the knee through a randomized controlled comparative study. They included 528 patients, of whom 264 were assigned to the PKR group and 264 were assigned to the TKR group, through a multicentre study involving 27 sites in the UK. At the 5-year follow-up, the authors found that both TKR and PKR were effective, the clinical outcomes were similar with no significant difference in Oxford Knee score, and the rate of re-operations and complications was identical. They also made a health economics analysis including the length of hospital stay and data on cost-effectiveness, and found that PKR was more effective and less expensive than TKR during the 5 years of follow-up. This was linked to slightly better outcomes, reduced costs of surgery, and follow-up health-care costs which were lower with PKR than TKR. The authors concluded that PKR should be considered the first choice for patients with advanced OA of medial knee compartment based on their clinical results and in light of reduced costs and better cost effectiveness with PKR during their study period.

The first point raised by the paper by Beard et al. (10) refers to the indications of respective procedures. Indeed, there has been considerable debate over the years regarding the ideal indications and contraindications of PKR since 
the classic 1989 article by Kozinn and Scott with strict indications (11). Thirty years later a recent consensus has been made to redefine the concept of PKR with a new and updated list of indications and contraindications for medial PKR (12). Interestingly in this paper it was strongly recommended that PKR should be reserved for patients with bone-on-bone disease severe enough to warrant consideration for total knee arthroplasty radiographically and clinically. This is precisely the scope of the paper by Beard et al. (10) since for study inclusion, participants had to have isolated $\mathrm{OA}$ of the medial knee compartment and to match the general indications for a medial PKR. The patients were then part of a large randomized trial which enables the authors to drive conclusion based on two very homogenous and comparable groups. This is a strength of the present study since although PKRs tend to have slightly better function, they may be performed in patients with better preoperative function. In order to avoid this potential bias, randomization is needed, which is the case in the current study.

The second point raised by the paper is the patient perception and satisfaction of the surgery at 5 years of follow-up, despite similar clinical scores between PKR and TKR patients. The authors found differences, both in favor of PKR, at 5 years in the results of the two questions:

(I) was your knee better to before the operation?

(II) would you have the operation again? This is in line with previous studies demonstrating better pain scores and function with PKR compared to TKR $(3,13)$, as well as quicker time to return to sport, including high impact sports, following PKR reported in meta-analysis study (8). The current randomized trial potentially avoids the various sources of heterogeneity often noted by the authors considering several studies included in metaanalysis review, and this added to the adequate power of the comparative trial is able to support the author's interpretation.

The third point, reporting the number of re-operations and revisions were similar between groups, will be more questionable since most joint registries, especially the one corresponding to the author's studying country, are reporting substantially larger number of revisions after PKR than after TKR (9). The results of the present paper are, however, in line with the 15 -year results reported by Newman et al. (1) in their prospective randomized trial, but the number of analyzed cases was much lower. They found less complications and more rapid rehabilitation for the PKR group than for the TKR group, and the failure rate was identical in the two groups. There are always been considerable debate on the differences found between registries data and single studies regarding the threshold for revision of PKR which might impact the results reported outside of a controlled trial. The current paper by Beard et al. (10) is also reporting that the frequency of complications was increased in the TKR group compared to the PKR group, similarly to the report of Arirachakaran et al. (2) in their systematic review and meta-analysis of randomized controlled trial. On the contrary, these authors found higher revision rate for PKR compared to TKR. In the US large database Hansen et al. were able to match based on the propensity score, 4,414 PKR patients to 86,935 TKR patients in the Medicare dataset, while 20,721 PKR patients were matched to 275,654 TKR patients in the MarketScan dataset (14). They reported less post-operative complications and re-admissions after PKR than after TKR, but with a higher rate of re-operation and revision at up to 10 years of follow-up. The interpretation of such discordant results should be made with caution since on one hand the advocate of TKR could argue that the failure rate reported in national registries give a good photography of the country perception of the procedure, but on the other hand the advocates of PKR can reply that the usual threshold for revising a PKR, especially for pain, is lower compared to TKR revision since it is well known the procedure is easier and the results better for PKR revision compared to TKR revision (15).

The last interesting point covered by Beard et al. is the health economic evaluation made by the authors which is an important aspect for the future in regards of the permanent augmentation of knee replacement to be performed in the coming years (16). The authors of the current paper did evaluate the total costs and quality-adjusted life-years (QALYs) for all 528 included participants of their study from the date of recruitment until the earliest of death or the end of follow-up at 5 years. In terms of health resource costs, they noticed that the operation time was similar in both groups, but the length of stay was significantly lower for PKR. They concluded that during the 5 years of follow-up, PKR was more effective but also less costly than TKR, based on the lower costs of the surgery and lower subsequent use of health-care services, such reduced outpatient visits during the first 2 years after surgery. These data may have relevance for other health-care systems than UK, based on the fact the established settings are similar. These findings about PKR expected to generate better 
health outcomes and lower lifetime costs than TKR were also recorded by Burn et al., however they noticed that a factor such surgeon volume for PKR has a significant impact on the cost-effectiveness of the procedure (17). To achieve the best results, surgeons need to perform a sufficient number of knee replacements as PKR. This last conclusion may have a direct impact on the organization of the heathcare system by addressing the patients to referred centers or on individual surgeon practice asking low PKR usage surgeons to broaden their indications for PKR. Interestingly these findings that PKR should be chosen over TKR in order to maximize cost-effectiveness were also recorded in the US by Kazarian et al., using a Markov decision analytic model, introducing also how lifetime costs and QALYs may vary as a function of age at the time of first treatment for patients with bone on bone unicompartmental knee OA (18). They concluded that expanding surgical options into younger and older age patients appears to be cost-effective in case of unicompartmental knee OA suggesting that nonsurgical treatments should be used sparingly in patients below 70 and PKR should be prioritized over TKR in order to maximize cost-effectiveness.

In real-life situations the choice between PKR and TKR in case of severe OA of the medial femoro-tibial compartment of the knee needs to be carefully evaluated with the available tools in order to maximize benefit to patients. These tools include clinical, cost-effectiveness and survivorship studies. We agree with the conclusions of the present study at 5 years of follow-up which tend to favor PKR due to slight better outcomes, lower costs of operation, and lower follow-up health-care costs with PKR than TKR. However, efforts should be made to confirm these results at 10 years of follow-up, usually considered as an important landmark for arthroplasty surgery. The factors which may change the paradigm for performing universally a PKR in case of OA limited to the medial compartment of the knee may include consensus indications including patient's age, surgical reproducibility and randomized control studies such the present one. Meanwhile each orthopedic surgeon should decide to replace either solely the affected compartment or the three compartments of the knee based on patient's characteristics and surgeon ability to perform each procedure.

\section{Acknowledgments}

Funding: None.

\section{Footnote}

Conflicts of Interest: All authors have completed the ICMJE uniform disclosure form (available at http://dx.doi. org/10.21037/atm.2020.01.131). Consultancy: ZimmerBiomet (JNAA), Stryker, Newclip (MO). CJ has no conflicts of interest to declare.

Ethical Statement: The authors are accountable for all aspects of the work in ensuring that questions related to the accuracy or integrity of any part of the work are appropriately investigated and resolved.

Open Access Statement: This is an Open Access article distributed in accordance with the Creative Commons Attribution-NonCommercial-NoDerivs 4.0 International License (CC BY-NC-ND 4.0), which permits the noncommercial replication and distribution of the article with the strict proviso that no changes or edits are made and the original work is properly cited (including links to both the formal publication through the relevant DOI and the license). See: https://creativecommons.org/licenses/by-nc-nd/4.0/.

\section{References}

1. Newman J, Pydisetty RV, Ackroyd C. Unicompartmental or total knee replacement: the 15 -year results of a prospective randomised controlled trial. J Bone Joint Surg Br 2009;91:52-7.

2. Arirachakaran A, Choowit P, Putananon C, et al. Is unicompartmental knee arthroplasty (UKA) superior to total knee arthroplasty (TKA)? A systematic review and meta-analysis of randomized controlled trial. Eur J Orthop Surg Traumatol 2015;25:799-806.

3. Lyons MC, MacDonald SJ, Somerville LE, et al. Unicompartmental versus total knee arthroplasty database analysis: is there a winner? Clin Orthop Relat Res 2012;470:84-90.

4. National Joint Registry for England \& Wales. Second Annual Report, September 2006. Available online: http:// www.njrcentre.org.uk/NjrCentre/Portals/O/Documents/ England/Reports/NJR_CR_3.pdf

5. Costa CR, Johnson AJ, Mont MA, et al. Unicompartmental and total knee arthroplasty in the same patient. J Knee Surg 2011;24:273-8.

6. Kulshrestha V, Datta B, Kumar S, et al. Outcome of Unicondylar Knee Arthroplasty vs Total Knee Arthroplasty for Early Medial Compartment Arthritis: A Randomized 
Study. J Arthroplasty 2017;32:1460-9.

7. Zhang Q, Guo W, Zhang Q, et al. Comparison of unicompartmental knee arthroplasty and total knee arthroplasty in the treatment of unicompartmental osteoarthritis: a meta-analysis. Curr Orthop Pract 2010:21:497-503.

8. Witjes S, Gouttebarge V, Kuijer PP, et al. Return to Sports and Physical Activity After Total and Unicondylar Knee Arthroplasty: A Systematic Review and Meta-Analysis. Sports Med 2016;46:269-92.

9. Liddle AD, Judge A, Pandit H, et al. Adverse outcomes after total and unicompartmental knee replacement in 101,330 matched patients: a study of data from the National Joint Registry for England and Wales. Lancet 2014;384:1437-45.

10. Beard DJ, Davies LJ, Cook JA, et al. The clinical and cost-effectiveness of total versus partial knee replacement in patients with medial compartment osteoarthritis (TOPKAT): 5-year outcomes of a randomised controlled trial. Lancet 2019;394:746-56.

11. Kozinn SC, Scott R. Unicondylar knee arthroplasty. J Bone Joint Surg Am 1989;71:145-50.

12. Berend KR, Berend ME, Dalury DF, et al. Consensus Statement on Indications and Contraindications for Medial Unicompartmental Knee Arthroplasty. J Surg Orthop Adv

Cite this article as: Argenson JNA, Jacquet C, Ollivier M. Medial femorotibial osteoarthritis of the knee: total or partial knee replacement? Ann Transl Med 2020;8(11):721. doi: 10.21037/atm.2020.01.131
2015;24:252-6.

13. Sun PF, Jia YH. Mobile bearing UKA compared to fixed bearing TKA: a randomized prospective study. Knee 2012;19:103-6.

14. Hansen EN, Ong KL, Lau E, et al. Unicondylar Knee Arthroplasty Has Fewer Complications but Higher Revision Rates Than Total Knee Arthroplasty in a Study of Large United States Databases. J Arthroplasty 2019;34:1617-25.

15. Lunebourg A, Parratte S, Ollivier M, et al. Are Revisions of Unicompartmental Knee Arthroplasties More Like a Primary or Revision TKA? J Arthroplasty 2015;30:1985-9.

16. Kurtz SM, Ong KL, Lau E, et al. Impact of the economic downturn on total joint replacement demand in the United States: updated projections to 2021. J Bone Joint Surg Am 2014;96:624-30.

17. Burn E, Liddle AD, Hamilton TW, et al. Costeffectiveness of unicompartmental compared with total knee replacement: a population-based study using data from the National Joint Registry for England and Wales. BMJ Open 2018;8:e020977.

18. Kazarian GS, Lonner JH, Maltenfort MG, et al. CostEffectiveness of Surgical and Nonsurgical Treatments for Unicompartmental Knee Arthritis: A Markov Model. J Bone Joint Surg Am 2018;100:1653-60. 